\title{
Peningkatan Mutu Produktivitas Aneka olahan Nanas Pada UMKM Nanas di Desa Tangkit Baru: Strategi Penanggulangan Karhutla
}

\author{
Yuliusman $^{1 *}$, Dedy Setiawan ${ }^{1}$, Husni Hasbullah ${ }^{1}$, Lucky Enggrani Fitri $^{1}$, \\ ${ }^{1}$ Fakultas Ekonomi dan Bisnis, Universitas Jambi, Indonesia \\ Penulis Korespondensi : yuliusraham@yahoo.co.id
}

\begin{abstract}
Abstrak: Sasaran pengabdian ini, adalah Usaha Mikro Kecil Menenggah (UMKM) di Desa Tangkit Baru yang mana pada saat ini memiliki permasalahan dalam hal pemasaran khususnya kesulitan dalam pemasaran produk olahan Nanas. Pengabdian ini, berupaya untuk memberikan pelatihan dalam hal pemasaran dan membuatkan media pemasaran berbasis web atau yang dikenal dengan E-Commerce untuk Mitra. Tujuan dengan adanya pengabdian ini, diharapkan bisa memperkenalkan produk-produk olahan nanas mereka lebih luas lagi melalui web dan dapat meningkatkan Omzet UMKM mitra.Peningkatan omzet ini diharapkan dapat menjadi magnet bagi masyarakatdi desa Tangkit Baru untukdapat meningkatkan kesejahteraan masyarakat di desa tersebut serta dapat mengubah kebiasaan petani di desa tersebut untuk menjadikan hasil pertaniaan mereka menjadi produk olahan dan juga diharapkan dengan kegiatan ini, akan mengubah kebiasaan petani di sana agar kedepannya menjual hasil perkebunan nanas dalam bentuk produk olahan sehingga dengan perubahan ini, tidak ada lagi petani yang ada disana membuka lahan yang baru yang bisa berdampak pada kebakaran lahan dan Hutan.
\end{abstract}

Kata kunci: Produk Olahan Nanas, Web, E-Commerce, Pemasaran.

\section{PENDAHULUAN}

Kebakaran lahan dan hutan (karhutla) di Provinsi Jambi pada tahun 2017 kembali terjadi. Berdasarkan data Meterologi Klimatologi dan Geofisika (BMKG) Stasiun Sultan Thaha dari bulan Januari hingga Desember ada 48 titik Hotspot yang tersebar di Provinsi Jambi (Oni, 2017). Kebakaran lahan dan hutan ini tersebar di beberapa daerah seperti di Kab Tanjung Jabung Timur, Tanjung Jabung Barat, Muaro Jambi,Batang hari, Tebo, Muara Bungo dan Kab. Tebo. Luas lahan yang mengalami kebakaran sepanjang tahun 2016-2017 mencapai 20 persen, hal ini terungkap dari hasil jumpa pers oleh walhi Jambi (Arnoldy 2017). Namun jumlah ini masih relative aman dibandingkan dengan kejadian kebakaran hutan yang terjadi pada tahun 2015, yang mana pada tahun 2015 tersebut menjadi kenangan yang buruk bagi masyarakat di Jambi akibat dampak terjadinya kebakaran lahan dan hutan pada tahun tersebut.

Kebakaran Lahan dan Hutan khususnya di Kabupaten Muaro Jambi, sering terjadi di Kec. Sungai Gelam karena di kecamatan ini memilliki lahan belukar yang luas dan sebagian daerahnya merupakan lahan Gambut seperti di sebagian daerah Desa Tangkit Baru. Pada tahun 2015 kebakaran yang terjadi di Kec. Sungai Gelam seluas 270 Hektare (Nursyifani, 2017). Pada tahun 2017, khususnya Di daerah Desa Tangkit Baru kembali telah terjadi lagi kebakaran hutan seluas $\pm 2 \mathrm{Ha}$ pada lahan belukar. Kebakaran ini terjadi disebabkan oleh ulah beberapa masyarakat di desa tersebut dalam membuka lahan baru untuk lahan perkebunan Nanas karena orientasi masyarkat di Desa tersebut semakin banyak lahan perkebunan yang dimiliki maka akan memberikan banyak keuntungan. Desa Tangkit Baru merupakan daerah yang mayoritas masyarakatnya berkebun Nanas. Kebiasaan masyarakat di daerah ini untuk membuka lahan baru dengan cara membakar lahan tersebut dikarenakan cara yang demikian merupakan cara yang paling cepat dan hemat.

Luas perkebunan Nanas di desa Tangkit Baru, Kec. Sungai Gelam, Kab. Muaro Jambi berjumlah \pm 1200 Ha dan Jumlah hasil panen buah Nanas perhari dari Desa Tangkit sebanyak $15.000 \mathrm{~s} / \mathrm{d} 20.000$ Buah. Melihat dari hasil ini. Tentu merupakan hasil yang luar biasa. Namun sangat disayangkan hasil ini belum benar-benar memberikan kontribusi yang besar terhadap 
kesejahteraan masyarakat di desa tersebut. Harga jual Nanas perbuah yang dijual petani ke pada pengumpul rata-rata dibawah Rp. 1.000 perbuahnya. Namun bila hasil nanas tersebut dijual dalam bentuk olahan seperti Dodol Nanas, Keripik Nanas, Selai Nanas dan Kue Nanas. Harganya lebih menjanjikan, seperti harga dodol Nanas Per-Kg Rp 30.000,-. UMKM Olahan produk nanas di desa ini belum begitu banyak di temuin, hal ini dikarenakan kekuatiran masyarakat sulitnya untuk dapat memasarkan produk olahan nanas di desa tersebut, sehingga factor-faktor ini yang menyebabkan masyarakat malas untuk merubah kebiasaan mereka untuk mengelolah hasil perkebunannya dalam bentuk produk olahan.

Melihat situasi yang demikian, tim mencoba merangkul beberapa UMKM produk olahan Nanas yang telah ada di desa tersebut untuk dijadikan mitra pengabdian ini seperti UMKM Tulimario yang dipimpin oleh H. Baso Intang, SE yang merupakan orang yang pertama mendirikan UMKM produk Olahan Nanas Pertama di desa tersebut dan beliau juga yang pertama pada tahun 1991 yang memiliki ide untuk menjadikan Buah Nanas sebagai bahan baku utama untuk pembuatan produk Dodol Nanas pertama di Indonesia, pada tahun 2013 beliau mendapat penghargaan dari Presiden Susilo Bambang Yudhoyono selaku pemilik usaha kecil yang berhasil. UMKM ini, pada saat ini telah memasarkan beberapa produk olahan Nanas dalam bentuk olahan seperti Dodol, Keripik, Selai, Kue Nanas. Pada saat ini semua supermarket di Jambi menjual hasil produk olahan nanas dari UMKM mereka. Omzet yang mereka dapati pada saat ini lebih kurang $40 \mathrm{~s} / \mathrm{d} 50$ juta perbulannya. H Baso Intang mengatakan kendala yang mereka alami selama ini terjadi dalam hal pemasaran dan sulitnya untuk memperkenalkan produknya ke luar Prov. Jambi. Sehingga belum begitu terkenalnya produk-produk mereka di luar Jambi, ini juga kenapa petani disini malas untuk mengubah kebiasaannya untuk menjadi buah Nanas jadi bahan olahan. Beliau mengatakan para wisatwan yang datang ke Jambi Hanya mengetahui oleh-oleh dari Jambi hanya pempek, padahal kalau bicara pempek di Prov. Palembang juga memiliki Pempek, artinya tidak ada perbedaan. Sedangkan dodol Nanas yang bahan bakunya dari buah Nanas menurut $H$. Baso hanya ada satu-satunya di Jambi tidak dimiliki oleh daerah lain.Oleh-oleh ini bisa menjadi Icon Jambi.

Pengabdian ini, berupaya untuk memberikan pelatihan dalam hal pemasaran dan membuatkan media pemasaran berbasis web atau yang dikenal dengan E-Commerce untuk masing-masing Mitra. Tujuan dengan adanya pengabdian ini, diharapkan bisa memperkenalkan produk-produk mereka lebih luas lagi dan dapat meningkatkan Omzet masing-masing UMKM sehingga dengan peningkatan ini dapat menjadi magnet bagi masrakat disana untuk dapat mengubah kebiasaan petani di desa tersebut untuk menjadikan hasil pertaniaan mereka menjadi produk olahan sehingga dengan perubahan ini, tidak ada lagi kedepannya petani didesa mitra yang membuka lahan baru untuk lahan perkebunan nanas sehingga dampak dari kebakaran lahan dan Hutan di lokasi mitra tidak terulang lagi dan dapat meningkatkan kesejahteraan masyarakat di desa tersebut.

\section{TARGET DAN METODE PELAKSANAAN}

Target dari pengabdian ini adalah bagaimana cara meningkatkan mutu Produktivitas dari produk-produk olahan Nanas dari Mitra sehingga pada akhirnya dapat meningkatkan kesejahteraan Mitra dan masyarakat sekitarnya dalam upaya mengurangi dampak kebakaran lahan dan hutan karena adanya pembukaan lahan baru di desa tersebut, sesuai dengan apa yang telah dianalisis secara sederhana pada pendahuluan. Adapun luaran dari kegiatan pengabdian masyarakat ini adalah Pembuatan teknologi tepat guna berupa Sistem E-Commerce Berbasis web dan peningkatan pemahaman manajemen strategi dalam pemasaran produk olahan Nanas 
oleh kedua mitra.Innovasi dalam program pengabdian ini berupa adanya Web E-Commerce yang akan dimiliki oleh Mitra.

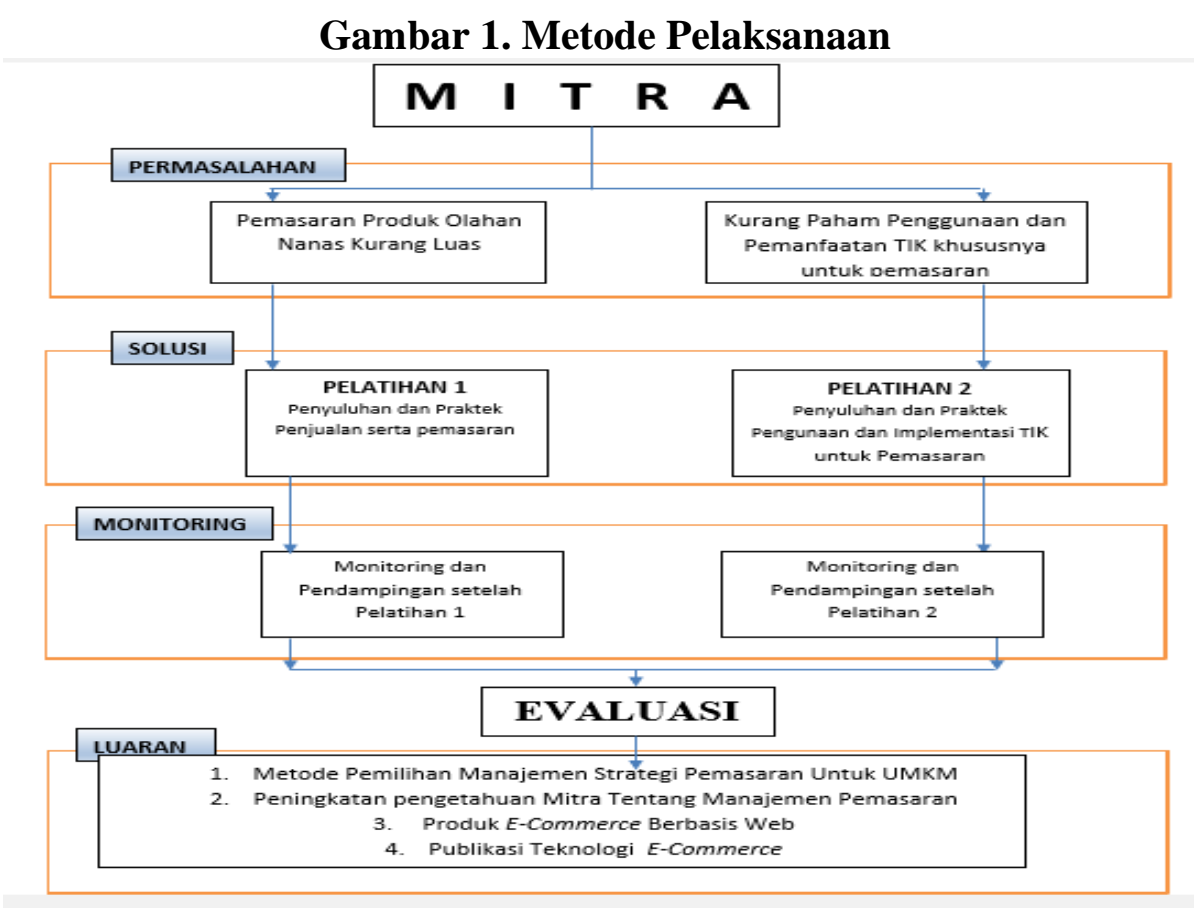

Metode pelaksanaan kegiatan menjelaskan tahapan atau langkah-langah dalam melaksanakan solusi yang ditawarkan untuk mengatasi permasalahan yang memuat hal-hal berikut ini.

a. Pihak-pihak yang terlibat dalam kegiatan penerapan pengabdian kepada masyarakat yaitu para dosen dan mitra binaan dengan memperhatikan saran dari pihak perangkat desa dalam hal ini, Kantor Desa Tangkit Baru.

b. Metode dan tahapan dalam penerapan pengabdian kepada masyarakat/mitra, mulai dari identifikasi kebutuhan mitra, perancangan, pembuatan, uji operasi, pendampingan operasional, dan penerapan pengabdian tersebut kepada masyarakat/Mitra.

c. Diskripsi pengabdian yang akan diterapkan ke masyarakat disertasi data yang mendukung (gambaran teknologi, desain, dll). pengabdian yang akan diterapkan kepada mitra adalah peningkatan pemahaman mitra dalam hal strategi pemasaran produk dan dibangunkan Teknologi E-Commerce, teknologi ini diharapkan dapat memberikan kemudahan kepada konsumen untuk dapat mengakses produk-produk yang tersedia yang dimiliki mitra melalui Teknologi E-Commerce berbasis Web. Dalam penamaan domain bisa disesuaikan dengan keinginan mitra.

d. Prosedure kerja untuk mendukung realisasi yang di tawarkan.

Teknologi E-commerce ini digunakan untuk membantu UMKM (Usaha Mikro dan Kecil Menengah), para pengusaha olahan produk Nanas bekerja secara efisen dan efektip. Teknologi ini didesain dalam bentuk yaitu bentuk E-Commerce berbasis web disesuaikan dengan keinginan mitra. UMKM nantinya akan diberikan pelatihan bagaimana cara mengoperasikan dari aplikasi ini dan mitra akan memiliki 1 user sebagai Admin di web $E$ Commerce sehingga UMKM mitra dapat menambah dan memperbaiki data (baik data produk, persedian barang) yang ada di masing-masing E-Commerce tersebut. Aplikasi ECommerce ini juga di rancang agar konsumen dapat bertransaksi melalui E-Commerce ini, sehingga seluruh aktivitas keuangan dapat ditercatat dengan baik dalam system $E$ - 
Commerce ini.sehingga dengan teknologi ini dapat memperluas pemasaran produk dan meningkatkan kepuasan, keamanan, kenyamanan bagi penggunanya. Setelah teknologi berhasil di implementasikan, selanjutnya akan di berikan pelatihan kepada pihak mitra untuk dapat mengunakan kedua aplikasi tersebut.

e. Partisipasi mitra dalam pelaksanaan program

Partisipasi mitra meliputi diskusi dengan dosen perguruan tinggi dan pemda dalam aktivitas berikut ini: survei penentuan tempat mitra binaan, penyusunan proposal, penentuan peserta untuk dilatih, pelatihan pengunaaan TIK, pelatihan pengolahan Aplikasi E-Commerce, pelatihan Manajemen pemasaran (baik offline maupun online), dan pelatihan kewirausahaan.

f. Evaluasi Pelaksanaan program dan keberlanjutan program setelah selesai kegiatan pengabdian Kepada Masyarakat di Lapangan.

- Partisipasi Masyarakat (level partisipasi masyarakat dalam pelaksanaan program, posisi strategis masyarakat sebagai elemen pelaksana, keterpaduan dan kebersamaan dengan PT dan Desa)

- Peningkatan Potensi Daerah (keberhasilan program dalam memanfaatkan potensi daerah, keserasian potensi daerah dan aktivitas program, ketepatan program terhadap persoalan wilayah).

\section{HASIL DAN PEMBAHASAN}

Saat ini kegiatan telah berlangsung, prioritas utama yang dilakukan adalah mempersiapkan software yang akan digunakan dalam rangka membantu UMKM mitra untuk memasarkan produk olahan nanas berbasis online(E-Commerce). Selanjutnya, mempersiapkan sarana pendukung berupa domain untuk web e-commerce yaitu

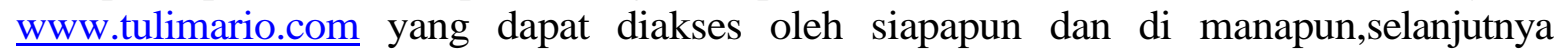
dilanjutkan dengan kegiatan berupa pelatihan dan demonstrasi langsung dilapangan dihadapan pengelolah e-commerce mitra UMKM serta pemantauan akhir dan keberlanjutannya.

Secara lebih rinci tahapan kerja pelaksanaan kegiatan dapat dilihat pada tabel 1 . dibawah ini.

\section{Tabel 1.}

Tabel Tahapan Kerja Pelaksanaan Kegiatan

\begin{tabular}{|c|l|c|c|c|}
\hline No & Jenis Kegiatan & Bentuk Kegiatan & Tujuan & Pelaksanaan \\
\hline 1. & Peningkatan & a. Pengurusan surat & & Sudah \\
& Mutu & perizinan & & \\
& Produktivitas & & & \\
& Aneka olahan & & \\
& Nanas Pada & & \\
& UMKM Produk & & & \\
& Nanas di Desa & & & \\
& Tangkit Baru, & & & \\
& Kec. Sungai & & \\
& Gelam, Kab. & & & \\
& Muaro Jambi & & & \\
& Bagi & & \\
& Meningkatkan & & & \\
& Taraf & & & \\
& Perekonomian & & & \\
Masyarakat & & & \\
\hline
\end{tabular}




\begin{tabular}{|c|c|c|c|c|c|}
\hline & & & $\begin{array}{l}\text { Survei } \\
\text { pendahuluan }\end{array}$ & $\begin{array}{l}\text { - } \begin{array}{l}\text { Diperlukan } \\
\text { untuk }\end{array} \\
\text { mendapatkan } \\
\text { informasi apakah } \\
\text { sumber daya yang } \\
\text { dimiliki oleh mitra } \\
\text { telah memadai atau } \\
\text { Tidak untuk digunakan } \\
\text { pada fase } \\
\text { - Pengembangan } \\
\text { selanjutnya } \\
\text { Mengetahui sebab } \\
\text { dan akibat yang } \\
\text { ditimbulkan dari } \\
\text { sistem yang sedang } \\
\text { berjalan } \\
\text { Mengetahui keinginan/ } \\
\text { apa yang diharapkan } \\
\text { oleh mitra }\end{array}$ & $\begin{array}{l}\text { Sudah } \\
\text { dilaksa } \\
\text { nakan }\end{array}$ \\
\hline & & c. & $\begin{array}{l}\text { Rakor tim } \\
\text { pelaksana dan } \\
\text { pengurus (Mitra) }\end{array}$ & & $\begin{array}{l}\text { Sudah } \\
\text { dilaksa } \\
\text { nakan }\end{array}$ \\
\hline & & d. & $\begin{array}{l}\text { Penyusunan } \\
\text { rencana kerja }\end{array}$ & & $\begin{array}{l}\text { Sudah } \\
\text { dilaksa } \\
\text { nakan }\end{array}$ \\
\hline & & e. & $\begin{array}{l}\text { Perancangan } \\
\text { dan Pembuatan } \\
\text { Program }\end{array}$ & \begin{tabular}{l} 
Menterjemahkan \\
keinginan mitra ke \\
Dalam bahasa \\
Komputer. \\
Perancangan ini \\
meliputi : Output, \\
Input, File-file, \\
Database, Komputer, \\
Bahasa yang \\
digunakan, Metode \\
\multicolumn{1}{c}{ dan prosedur, } \\
Pengendalian intern. \\
Pembuatan program \\
yang telah disepakati \\
\end{tabular} & $\begin{array}{l}\text { Sudah } \\
\text { dilaksanakan }\end{array}$ \\
\hline & & & Evaluasi awal & & $\begin{array}{l}\text { Sudah } \\
\text { dilaksanakan }\end{array}$ \\
\hline \multirow[t]{5}{*}{2.} & $\begin{array}{l}\text { Peningkatan } \\
\text { pengetahuan } \\
\text { Pengelolah tentang } \\
\text { Dampak Kebakaran } \\
\text { hutan dan E- } \\
\text { Commerce }\end{array}$ & & $\begin{array}{l}\text { Penyuluhan dan } \\
\text { pengenalan dampak } \\
\text { kebakaran hutan dan } \\
\text { E-commerce }\end{array}$ & $\begin{array}{l}\text { Memperkenalkan serta } \\
\text { menjelaskankepada } \\
\text { para mitra tentang E- } \\
\text { Commerce dan } \\
\text { Dampak Kebakaran } \\
\text { Hutan } \\
\end{array}$ & $\begin{array}{l}\text { Sudah } \\
\text { dilaksanakan }\end{array}$ \\
\hline & & & $\begin{array}{l}\text { Bimbingan } \\
\text { E-Commerce }\end{array}$ & & $\begin{array}{l}\text { Sudah } \\
\text { dilaksanakan }\end{array}$ \\
\hline & & & $\begin{array}{l}\text { Bimbingan } \\
\text { penggunaan } \\
\text { program } \\
\text { E-Commerce } \\
\end{array}$ & & $\begin{array}{l}\text { Sudah } \\
\text { dilaksanakan }\end{array}$ \\
\hline & & & Evaluasi akhir & & $\begin{array}{l}\text { Sudah } \\
\text { dilaksanakan }\end{array}$ \\
\hline & & & $\begin{array}{l}\text { Bimbingan input } \\
\text { transaksi satu }\end{array}$ & & $\begin{array}{l}\text { Sudah } \\
\text { dilaksanakan }\end{array}$ \\
\hline
\end{tabular}




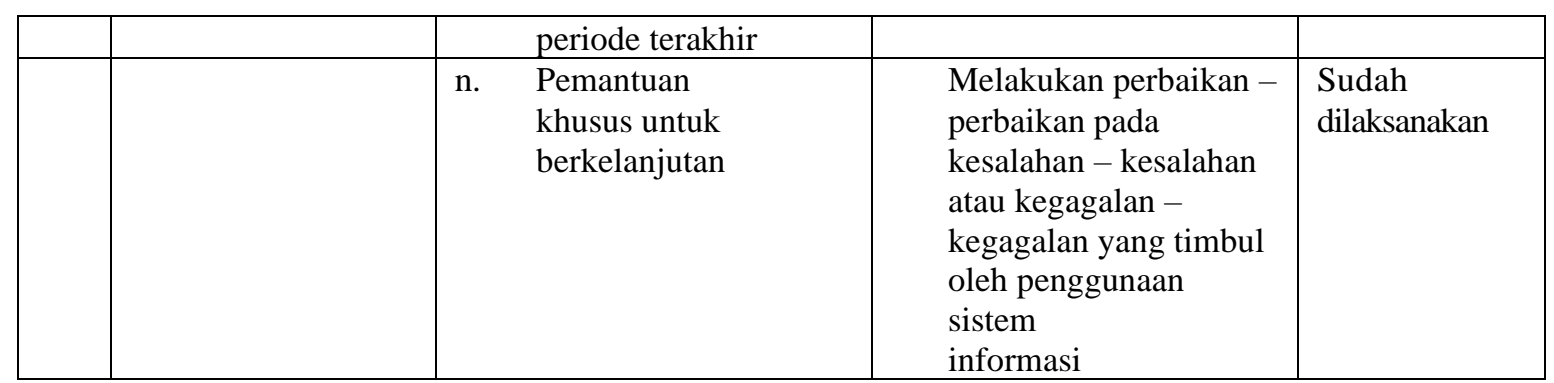

\section{Gambar 2. Tampilan Awal web UMKM (www.tulimario.com)}
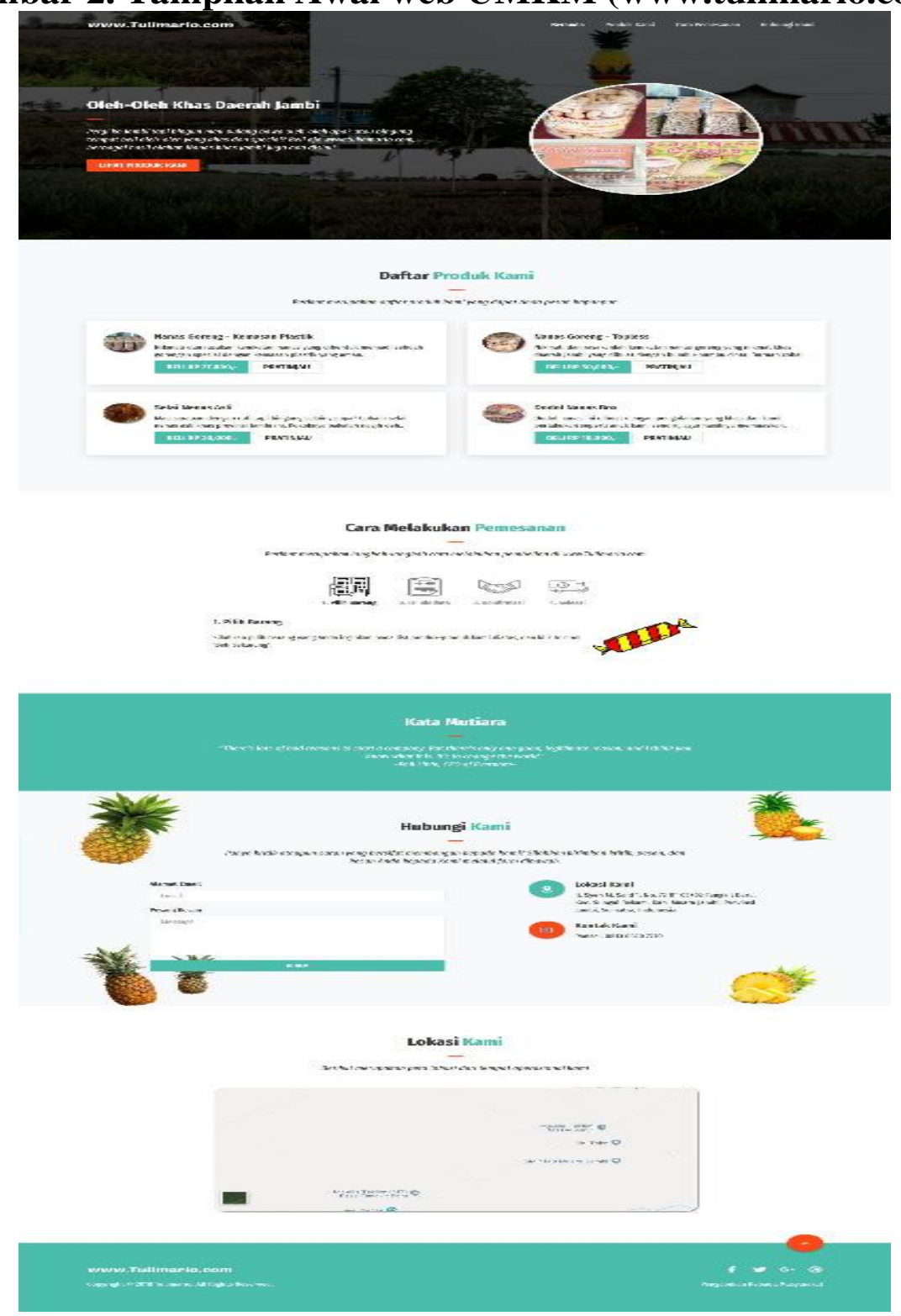

Gambar 3. Daftar Produk Olahan UMKM 


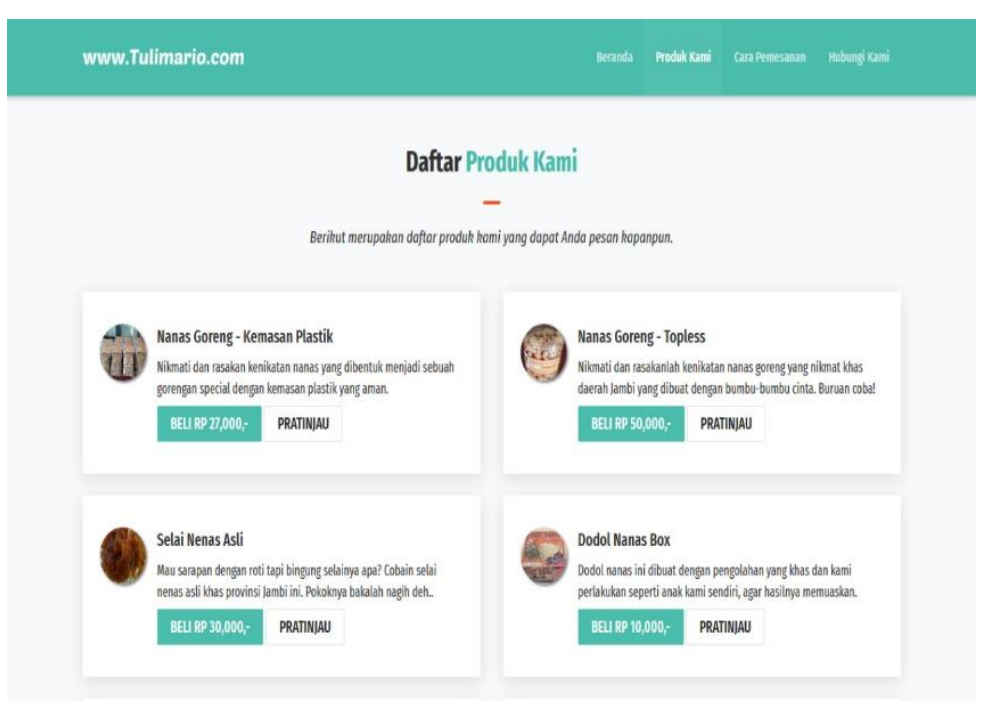

\section{KESIMPULAN}

Hasil dari kegiatan pengabdian ini adalah adanya motivasi dari para pengurus UMKM dan masyarakat di desa Tangkit Baru untuk memproduksi produk-produk olahan nanas dan memanfaatkan Teknologi inforamsi yaitu webe-commerce yang dibangun dalam rangka meningkatkan mutu penjualan produk olahan nanas dari desa tersebut, dimana sebelumnya masyarakat tidak mau membuat olahan nanas dan penjualan produk olahan nanas dilakukan secara manual.

\section{SARAN}

Perlu adanya peranan stakeholder seperti pemerintahan daerah khususnya dinas koperasi dan UMKM kab. Muaro Jambi yang terkait dengan pengembangan sistem ecommerce produk-produk UMKM sehingga kedepannya proses pembuatan dan pengembangan aplikasi tersebut dapat berjalan sesuai dengan apa yang dinginkan oleh pihak mitra dan masyarakat di desa Tangkit Baru, Kec. Sungai Gelam, Kab. Muaro JambiProvinsi Jambi.

\section{DAFTAR PUSTAKA}

Arnoldy, Andika 2017 "20 Persen Lahan dan Hutan Jambi Musnah Terbakar di 2017" dari http://jambi.tribunnews.com/2017/12/27/20-persen-lahan-dan-hutan-jambi-musnahterbakar-di-2017. Dikutip 17 Februari 2018

Nursyifani, 2017,"Kebakaran Hutan Belajar Dari Memori 2015", dari http://kalimantan.bisnis.com/read/20170908/452/687885/kebakaran-hutan-belajardari-memori-2015. Dikutip 17 Februari 2018

Oni, 2017, "BMKG Deteksi Sembilan Titik Panas di Jambi", dari http://nasional.harianterbit.com/nasional/2017/09/17/87033/0/20/BMKG-DeteksiSembilan-Titik-Panas-di-Jambi. Dikutip 17 Februari 2018 